\title{
The Green Synthesize of Zinc Oxide Catalyst Using Pomegranate Peels Extract for the Photocatalytic Degradation of Methylene Blue Dye
}

\author{
Atheel Alwash \\ Department of Chemistry, College of Science, AL-Nahrain University, Baghdad, Iraq. \\ E-mail: atheelalwash@yahoo.com \\ ORCID ID: https://orcid.org/0000-0003-4909-2164
}

Received 5/5/2019, Accepted 7/1/2020, Published 1/9/2020

This work is licensed under a Creative Commons Attribution 4.0 International License.

\begin{abstract}
:
In this study, the zinc oxide NPs have been synthesized from the fresh pomegranate peels extract using the precipitation method. The $\mathrm{ZnO}$ nanoparticles were produced from the reaction of fresh peels extract with zinc acetate salt which was used as zinc source in the presence of $2 \mathrm{M} \mathrm{NaOH}$. The green synthesized nanoparticles were characterized through X-ray diffraction (XRD), UV-Vis diffuse reflection spectroscopy, Fourier transform infrared spectroscopy (FTIR), and Atomic force microscopy (AFM). The XRD patterns confirm the formation of hexagonal wurtzite phase structure for $\mathrm{ZnO}$ synthesized using pomegranate peels extract with average crystalline size of $28 \mathrm{~nm}$. FTIR spectra identify the presence of many active functional groups for the pomegranate extract which is ideal to bind with zinc acetate to produce the $\mathrm{ZnO}$ nanoparticles during the preparation method. The reflection spectra of green synthesis $\mathrm{ZnO}$ with pomegranate extract observed a blue shift towards lower wavelength with $(8 \mathrm{~nm})$ difference compared to $\mathrm{ZnO}$ without the addition of any extract. The provenance of such blue shift towards shorter wave length was due to the quantum size effect. The Atomic force microscopic (AFM) result shows average roughness value for $\mathrm{ZnO}$ nanoparticles of $6.26 \mathrm{~nm}$. The decolorization efficiency of the methylene blue dye was investigated using the $\mathrm{ZnO}$ nanoparticles under sun light irradiation and it was compared with the bare $\mathrm{ZnO}$ synthesized without the addition of extract. The catalytic activity was about $88 \%$ after $60 \mathrm{~min}$ of sunlight irradiation for both prepared catalyst however, the decolorization efficiency of $\mathrm{ZnO}$ with the addition of extract was higher at the first 16 min compared to bare $\mathrm{ZnO}$.
\end{abstract}

Key words: Green synthesize, Methylene blue, Photocatalytic reaction, Pomegranate Peels, Zinc oxide.

\section{Introduction:}

Dyes with their tremendous varieties are a symbol for one of the largest groups of organic compounds that have a great effect on increasing the environmental danger. The pollutions generated by these dyes and textile industries include considerable amounts of non-fixed dyes and huge amount of inorganic salts (1). During the last decade, many novel waste water treatment technologies have been widely developed. These technologies can be classified into separation, degradation and elimination processes that applied on different polluting agents discharged from the industrial sector (2). However, these methods could not be suitable to degrade all kinds of pollutant due to the wide variety in chemical structure. As such, further investigation was needed.

Recently, different advanced oxidative processes that completely or partially degrade the dyes into non-toxic end products are reported (3).
The photocatalysis was one of the most efficient and an economical method under visible light irradiation (4). The principles of the photocatalytic reaction based on the generating of an electron-hole pair that consider as a spark for the starting of a series for the degradation reactions of organic compounds (5). One of the most active species generated from the irradiation of photocatalyst is hydroxyl radicals which is associated with oxygen to achieve a complete mineralization of organic pollutants into $\mathrm{CO}_{2}, \mathrm{H}_{2} \mathrm{O}$ and other nontoxic products (6).

During the last decade, different types of semiconducting photocatalyst have been investigated i.e. $\mathrm{TiO}_{2}, \mathrm{Fe}_{2} \mathrm{O}_{3}, \mathrm{ZnS}, \mathrm{WO}_{3}, \mathrm{CdS}$ and $\mathrm{ZnO}$ (7). Zinc oxide has been used in wide fields including electronics, optics, and biomedical systems due to its low cost to produce, safe and can be prepared easily. Furthermore, zinc oxide has 
interesting optical properties represented by its large band gap $(3.37 \mathrm{eV})$ and high excitation binding energy $(60 \mathrm{meV})$ like high catalytic activity, optic, UV filtering properties, anti-inflammatory and wound healing (8).

During the last few years, various preparation methods have been developed for the production of $\mathrm{ZnO}$ NPs, such as reaction of zinc with alcohol, vapor transport, hydrothermal synthesis, precipitation method etc. However, these traditional preparation methods suffer various disadvantages due to the sever condition that may be used such as the high temperature / pressure conditions and the use of toxic chemicals (9).

The green synthesis technology was moved toward the preparation of nanoparticles using microorganisms, fruits, bacteria, fungi, alga and plants. This approach is an environment-friendly, cost- effective, biocompatible, safe and green approach. The green synthesis technology allows the production of a big scale of $\mathrm{ZnO}$ NPs free of extra impurities (8).

In recent years, the productions of different kinds of nanoparticles have been generated from the plants and plant parts. The plants extracts may contain several natural compounds such as alkaloids, flavonoids, saponins, steroids, tannins, and other nutritional compounds. The source of such natural products are represented from leaves, stems, roots, shoots, flowers, barks, and seeds where they act as reducing and stabilizing agents for the bio-reduction reaction in the synthesis of metallic nanoparticles (10).

In this work, zinc oxide has been synthesized as a green environmental catalyst using pomegranate peels extracts for the removal of methylene blue dye under sunlight irradiation. The use of peels extract is a green approach that allows the production of active catalyst without the addition of any expensive and harms materials. Furthermore, the peels extract is consider as natural source act as effective capping and reducing agent to reduce the agglomeration of the nanoparticles. The green synthesized catalyst was characterized using different characterization techniques including XRD, FTIR, diffuse reflect spectra, and AFM technique. The efficiency of the produced catalyst was detected under sunlight irradiation for the color removal of methylene blue dye which was used as a pollutant model in this study.

\section{Materials and Methods:}

The zinc acetate dihydrate as a raw material was purchased from GPR. The sodium hydroxide was purchased from Merck. On the other hand, methylene blue dye was obtained from Fluka. Table 1 , lists the structure and properties of methylene blue dye as in below:

Table 1. The structure and properties of Methylene blue dye

Molecular
structure

\section{Preparation of Pomegranate Peel}

In this research, the fresh and cleaned pomegranate peels were used to collect their extracts by taking $50 \mathrm{~g}$ of fresh pomegranate peels and transferred into $500 \mathrm{ml}$ glass beaker along with $400 \mathrm{ml}$ of distilled water. The mixture was allowed to boil for about $10 \mathrm{~min}$. The color of mixture solution changed from colorless to brown (11). Next, the mixture was allowed to settle and cooled to room temperature and filtered with Whatman No. 1 filter paper. In all experiments the pomegranate extract was used as fresh liquid.

\section{Green Synthesis of Zinc Oxide Nanoparticles}

For the preparation of zinc oxide nanoparticles, $8 \mathrm{~g}$ of zinc acetate dihydrate was dissolved in $400 \mathrm{ml}$ of the distilled water and stirred for $5 \mathrm{~min}$ at room temperature. The peels extract $(\mathrm{pH} 5)$ was added to the solution and adjusted by $\mathrm{NaOH}$ to $\mathrm{pH}$ 12. The obtained mixture was left under stirring at room temperature for $2 \mathrm{hrs}$ (11). Then the mixture was filtrate and washed with distilled water several times. Finally the precipitate wet powder was dried in oven at $80^{\circ} \mathrm{C}$ for $24 \mathrm{hrs}$ and kept for further experiments.

\section{Reaction and Analytical Methods}

The photo activity for the prepared zinc oxide catalyst was tested towards the removal of methylene blue dye. The methylene blue dye was used as a pollutant model in this reaction. A conical flask of $250 \mathrm{~mL}$ was used as a reactor equipped with mechanical stirrer to ensure consistent mixing of solution in the reactor. Before the starting to sunlight irradiation, the solid catalyst was mixed in dark for $30 \mathrm{~min}$ to confirm the liquid/solid phase equilibrium. The acidity of solution was tested using pH-BP3001 Trans instruments digital $\mathrm{pH}$ meter. Later, the decolorization reaction of dye solution was started using sun light/solid catalyst with constant stirring for $1 \mathrm{hr}$. The samples were taken at periodic intervals i.e. $(10 \mathrm{~min})$. The 
spectrophotometric analysis was used to detect the maximum absorption length of the methylene blue dye which was $652 \mathrm{~nm}$. The dye solution concentration of the dye solution was calculated based on the maximum absorbance wavelength using Beer-Lambert law. The catalytic activity represented by the color removal was calculated (12) based on equation (1)

Decolorization Efficiency \% $=\left[1-\frac{C t}{C 0}\right] * 100 \% \ldots$ (1)

Where, $C_{o}$ is concentration of dye in $(\mathrm{mg} / \mathrm{L}), C_{t}$ is the concentration of dye in $(\mathrm{mg} / \mathrm{L})$ at different reaction time and $\mathrm{t}(\mathrm{min})$.

\section{Characterization Techniques}

The characterization of the catalyst with different analytical techniques was performed on the catalyst. The X-ray diffraction (XRD)/Shimadzu were performed with a $\mathrm{Cu} \mathrm{K}$ _ target at $40 \mathrm{kV}$ and $30 \mathrm{~mA}$. The Fourier transforms infrared spectroscopy analysis was carried out using Bruker Alpha spectrophotometer. Meanwhile, the reflection spectra of the solid samples were measured using the diffraction spectrophotometer (Elmer) with a wavelength range between 190 and 1,300 $\mathrm{nm}$. The roughness of the catalyst surface was checked using Atomic force microscopic (AFM) technique.

\section{Results and Discussion X-ray Diffraction Analysis}

The crystalline characteristic and the average crystalline size of the $\mathrm{ZnO}$ NPs were further investigated using XRD. Figure 1 presents the diffraction peaks for the green synthesized $\mathrm{ZnO}$ catalyst prepared with the addition of pomegranate peels extract. The finger prints of the XRD pattern confirm the hexagonal wurtzite phase structure of $\mathrm{ZnO}$. The results revels the formation of $\mathrm{ZnO}$ phase with a good crystallanity. Several diffraction peaks were detected i.e. $31.7,34.4,36.2,47.5,56.5,62.8$ and 67.9. These results were in good agreement with (13) and (14). The average crystalline size for $\mathrm{ZnO}$ synthesized with pomegranate peels extract was $28 \mathrm{~nm}$ which was calculated based on Scherer equation.

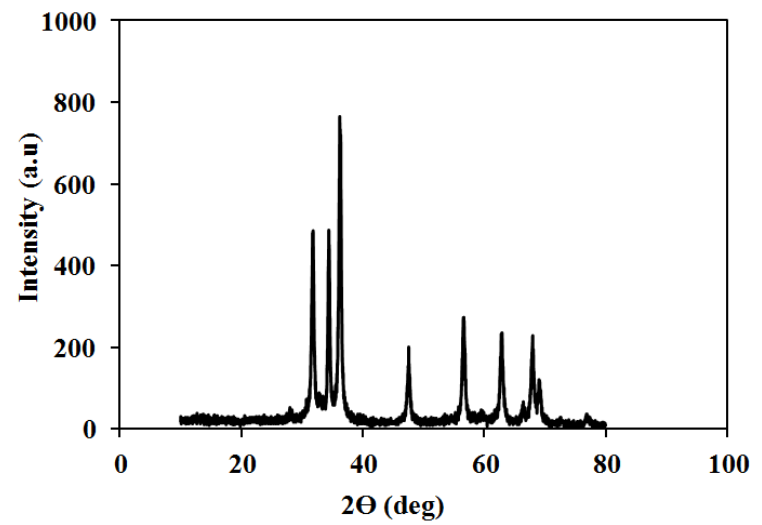

Figure 1. XRD of the green synthesized $\mathrm{ZnO}$ catalyst using pomegranate peels extract

\section{Fourier Transforms Infrared Spectroscopy}

The FTIR technique was used to identify the functional groups of the active component. The FTIR spectra for the green synthesized catalyst $(\mathrm{ZnO})$ was investigated and compared with the pomegranate extract as shown in Fig. 2 (a, b). A broad band at $3267 \mathrm{~cm}^{-1}$ was observed for pomegranate extract that refers to alcohol, phenol, or $\mathrm{O}-\mathrm{H}$ stretching band. However, this band was reduced after the reaction between the zinc acetate and the pomegranate extract during the preparation method of $\mathrm{ZnO}$ NPs and a band was detected at $3367.7 \mathrm{~cm}^{-1}$. In Fig. 2 (a), the absorption peak at $2109.4 \mathrm{~cm}^{-1}$ was attributed to alkyne $\mathrm{C} \equiv \mathrm{C}$ stretching; this band was shifted to 2317 for the FTIR spectra of $\mathrm{ZnO}$.

In Fig. 2 (a) the band at $1636.5 \mathrm{~cm}^{-1}$ refers to amide carbonyl group in amide I and amide II (15). However, in Fig. 2 (b) two new band were formed at $1554.7 \mathrm{~cm}^{-1}$ and $1410.5 \mathrm{~cm}^{-1}$ referred to methylene scissoring vibration from the proteins (13) . Many absorption bands were detected for the green synthesized catalyst $\mathrm{ZnO}$ that could not be observed in the FTIR of pomegranate extract i.e., the bands at $1240.3 \mathrm{~cm}^{-1}, 1018.4 \mathrm{~cm}^{-1}, 844.6 \mathrm{~cm}^{-1}$, $794.6 \mathrm{~cm}^{-1}$ and $552.9 \mathrm{~cm}^{-1}$ which could refer to phenols and C-N stretching vibration of amine, $\mathrm{C}-\mathrm{O}$ stretching vibrations of alcohols band and aromatics compounds respectively. Similar results were detected with (13) they also suggest that these functional groups act as dispersing, capping, and stabilizing agents for $\mathrm{ZnO}$ NPs during the preparation methods. Thus, that pomegranate peels extract can bind to zinc oxide nanoparticles through these groups. 

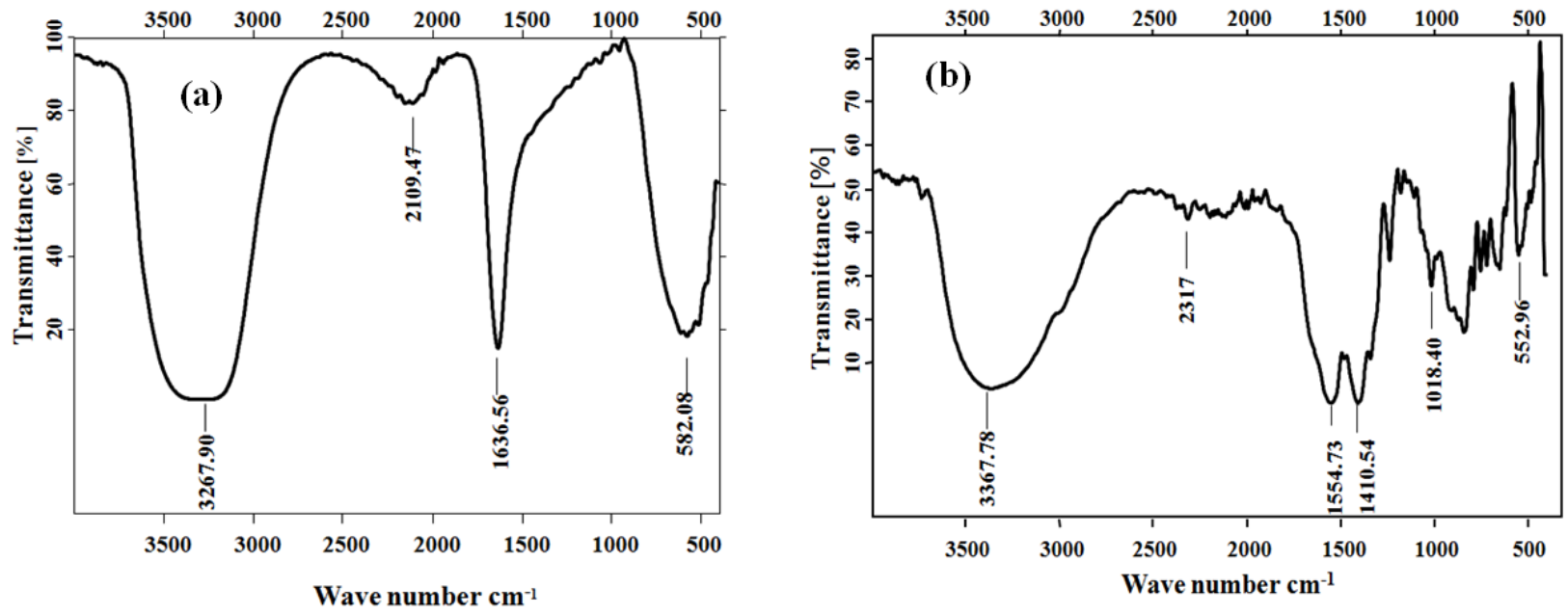

Figure 2. FTIR of (a) pomegranate extract (b) $\mathrm{ZnO}$ with the addition of extract

\section{UV-VIS Diffuse Reflectance Spectra}

The reflection spectra and the optical properties of the green synthesized $\mathrm{ZnO}$ nanoparticles were measured by the UV-Vis diffuse reflectance spectra and compared to $\mathrm{ZnO}$ prepared by precipitation method without the addition of peels extract as in Fig. 3 over the wavelength from 200-1200 nm. The bare $\mathrm{ZnO}$ prepared without the addition of extract shows a reflection spectrum at $414 \mathrm{~nm}$ see Fig. 3 (a). Meanwhile, $\mathrm{ZnO}$ prepared with pomegranate peels extract shows reflection spectra at $406 \mathrm{~nm}$ as in Fig.3 (b). The rapid drop in the reflectance spectra at a certain wave lengths indicated the presence of an optical band gap for the prepared samples. Similar results were detected by (16).
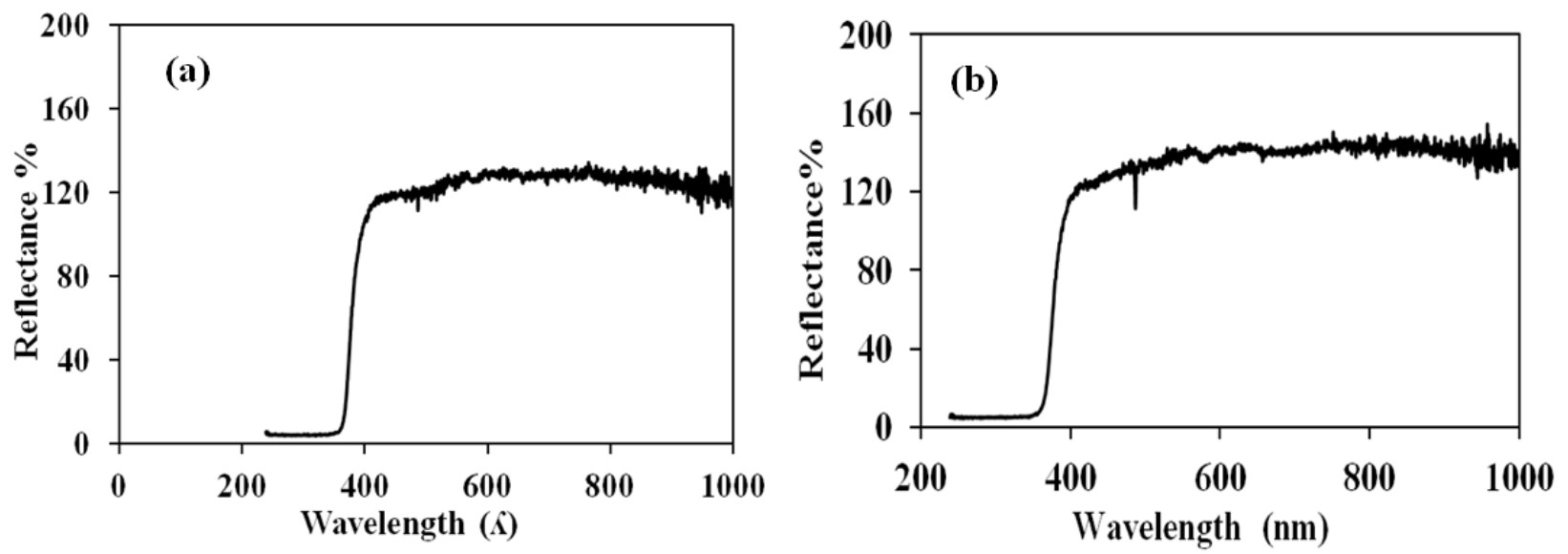

Figure3. UV-VIS diffuse reflectance spectra of $\mathrm{ZnO}$ (a) Without the addition of extract (b) With the addition of extract

The estimated energy band gap of the samples was calculated by the extrapolation of the straight line for the graph plotted between the square $\mathrm{Ln}\left[\left(\mathrm{R}_{\max }-\mathrm{R}_{\min }\right) /\left(\mathrm{R}-\mathrm{R}_{\min }\right)\right]$ versus $\mathrm{h} v$ (as abscissa) (17) as in Fig. 4 (a,b). The results show that the green synthesis catalyst has an energy gap of $3.45 \mathrm{ev}$ which is slightly higher than the $\mathrm{ZnO}$ prepared chemically with an energy band gap of $3.41 \mathrm{ev}$. The slight increase in semiconductor band gab represented by the blue shift towards shorter wave length reflects theoretically the decreasing in its particle size. As such, a large redox potential will be produced due to this band edges shift. Consequently, the valence band levels are moderately shifted to lower energies; meanwhile the levels of the conduction band are strongly shifted to higher energies (18). 

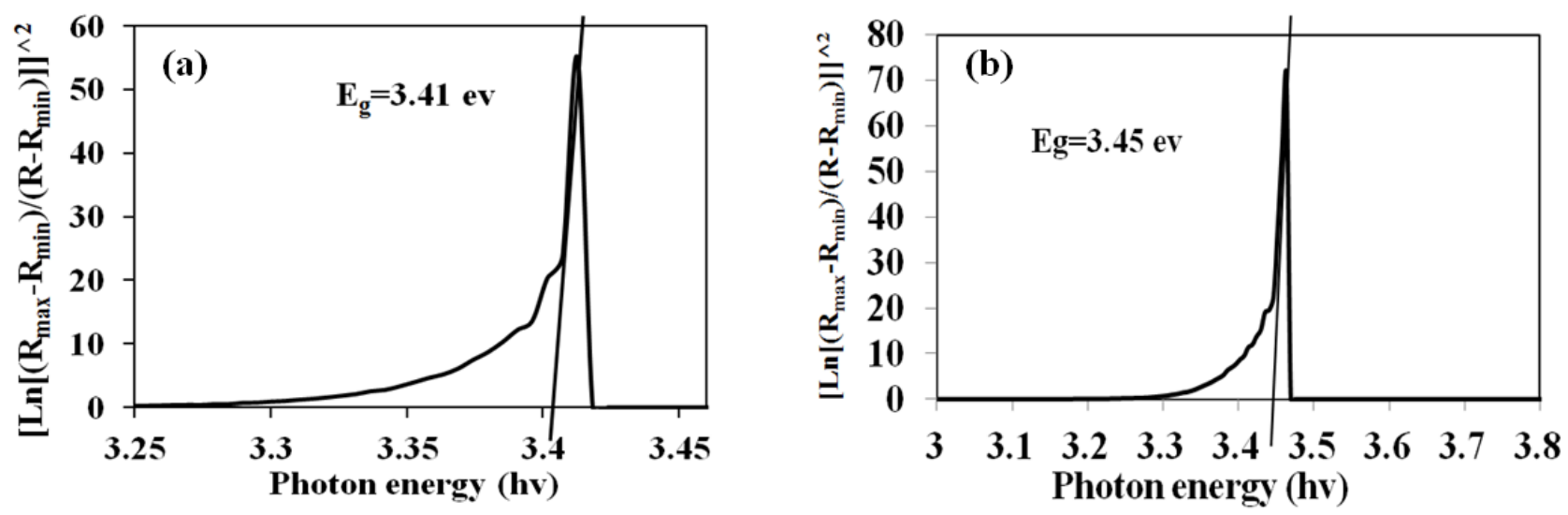

Figure 4. The energy band gap of $\mathrm{ZnO}$ (a) without the addition of extract (b) with the addition of extract

In this study, the reflection spectra of green synthesis $\mathrm{ZnO}$ with pomegranate extract observed a blue shift towards lower wavelength with $(8 \mathrm{~nm})$ difference compared to $\mathrm{ZnO}$ without the addition of any extract. The shifting of the wave length towards shorter wave length was due to the quantum size effect. Similar result was reported by (19). The size quantization is termed on nano-scales particles that showed a reduction in their particles size and led to an enhancement in the active surface area of the sample. As such, more light with short wavelength and energy higher than the band gap energy of semiconductors would be absorbed to assist the excitation of electron (20). Observing these optical properties of our synthesized $\mathrm{ZnO}$ catalyst using pomegranate peels extract indicated the successful synthesis of nanoparticles due to the quantum size effect.

\section{Atomic Force Microscopy}

The Atomic Force Microscopy 3D image was introduced to the $\mathrm{ZnO}$ prepared by the addition of pomegranate peels extract to investigate the surface topography as in Fig. 5. This was detected by evaluating the average roughness surface of the prepared catalyst. The result showed an average roughness value for $\mathrm{ZnO}$ with the addition of pomegranate peels extract of $6.26 \mathrm{~nm}$. According to the AFM 3D image, it was clear that the surface moroghology of $\mathrm{ZnO}$ was not smooth and has an agglomerated particles represented by the white peaks. This agglomeration could be ascribed to the measurement technique.

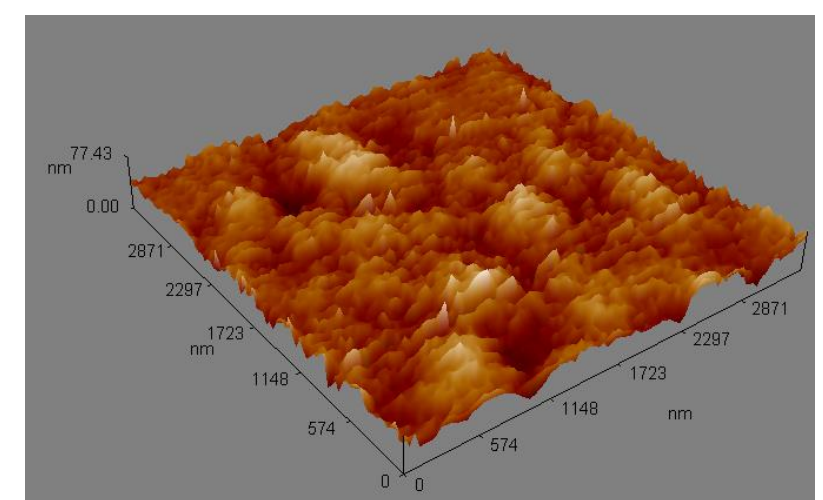

Figure 5. AFM 3D image of $\mathrm{ZnO}$ catalyst

\section{Control Experiments}

The catalytic activity of zinc oxide for the methylene blue dye removal was investigated; under different conditions i.e, $\mathrm{ZnO}$ (with pomegranate peels extract) under sun light irradiation, $\mathrm{ZnO}$ (with pomegranate peels extract) in dark, without the presence of catalyst and bare $\mathrm{ZnO}$ synthesized without the addition of extract. All the reactions were carried out with $10 \mathrm{mg} / \mathrm{L}$ dye concentration, $\mathrm{pH}$ around 5.6, catalyst loading of $1.5 \mathrm{~g} / \mathrm{L}$ with $60 \mathrm{~min}$ of reaction time as in Fig. 6. No color removal was observed for the dye solution alone without any addition of catalyst under sun light irradiation. The insufficient amount of $\mathrm{OH}$ radicals generated by photolysis process causes this low decolorization efficiency (21) since the radicals formed in photolysis process were generated only through the dissociation of water molecules. Besides, the efficient hydroxyl radicals are non selective and have very short life time that reduces their possibility to react with the dye molecules consequently, reducing the probability to obtain complete color removal. However, as the green synthesized $\mathrm{ZnO}$ catalyst was added to the dye solution in dark, the absorption rate of catalyst was about $23 \%$ after $30 \mathrm{~min}$ of mechanical stirring.

On the other hand, the photocatalytic activity for the green synthesized catalyst (i.e. $\mathrm{ZnO}$ 
with the addition of extract) was investigated under sun light irradiation. Before the starting of irradiation with sun light, the catalyst was mixed with dye solution to obtain the adsorption/desorption equilibrium for $30 \mathrm{~min}$ as in Fig. 6. The maximum absorption rate for the $\mathrm{ZnO}$ with the addition of extract was about $23 \%$. Meanwhile, as the reaction solution was subjected to sun light irradiation, the decolorization rate began to increase with maximum catalytic activity of $88 \%$ after $60 \mathrm{~min}$ of sunlight irradiation for $\mathrm{ZnO}$ with the addition of extract. This enhancement in photocatalytic activity was ascribed to the activation of the solid catalyst under sun light that improved the generation of more free radicals. The irradiation of semiconductor by photolysis process excites an electron from the valence band to the conduction band thus leaving a hole in the valence band leading to generation of electron/hole pairs. At the surface of the photo excited semiconductor catalyst, both reduction and oxidation processes could occur (22).

The catalytic activity of the green synthesized catalyst was compared with bare $\mathrm{ZnO}$ prepared without the addition of any pomegranate peels extract. The result shows maximum absorption ability of $23 \%$ after $30 \mathrm{~min}$ of mechanical stirring and $86 \%$ of catalytic activity after 60 min of sunlight irradiation. In Fig. 6 it was clear that decolorization efficiency of $\mathrm{ZnO}$ with the addition of extract was higher at the first $16 \mathrm{~min}$ compared to bare $\mathrm{ZnO}$ however as the time was steps forward both catalyst reached to similar activity after $60 \mathrm{~min}$ of sunlight irradiation. The similarity in catalytic activity for both $\mathrm{ZnO}$ synthesized with and without the pomegranate peels extract was ascribed to the slight difference in their energy band gap.

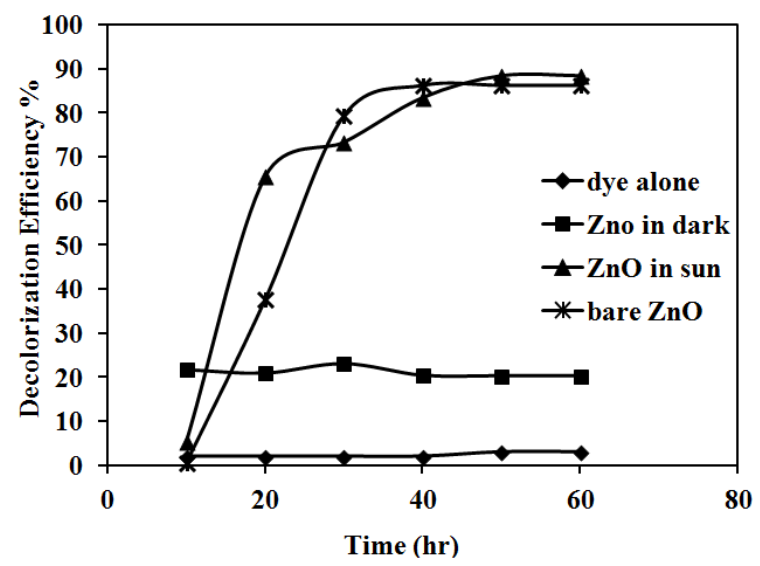

Figure 6. Decolorization efficiency of $\mathrm{ZnO}$ under different condition

\section{Mechanism of Reaction}

Figure7 explains the principles of photocatalysis reaction process through a series of reaction occurred on the surface of ZnO NPs. The mechanism of the photocatalytic reaction normally can be divided into 4 steps i.e. photoexcitation, charge separation, migration, and surface oxidation-reduction reactions (23).

The $\mathrm{ZnO}$ Photocatalysis can be irradiated by placing $\mathrm{ZnO}$ NPs suspension under natural sunlight. The exited electron (e) will be transferred from the valence band (VB) to the conduction band (CB) of semiconductor by absorbing UV-light energy higher than its energy gab thus, generates the $\left(\mathrm{e}^{-}-\mathrm{h}^{+}\right)$pair. The $\left(\mathrm{e}^{-}-\mathrm{h}^{+}\right)$pair can be either recombine with each other or initiates by a series of photo-reactions that may occur by two routes 1) the direct oxidation of the dye molecules by the formed hole or the exited electron as in Fig. 7 (a) 2) oxidation of the dye molecules through the $\mathrm{OH}^{\circ}$ radicals generated from the oxidation of water or $\mathrm{OH}^{-}$by the $\mathrm{h}^{+}$or oxygen radicals $\left(\mathrm{O}_{2}{ }_{2}, \mathrm{O}^{*}\right)$ which have strong oxidizing properties that generated from the oxidation of the absorbed oxygen on the catalyst surface (20) as in Fig. 7 (b).

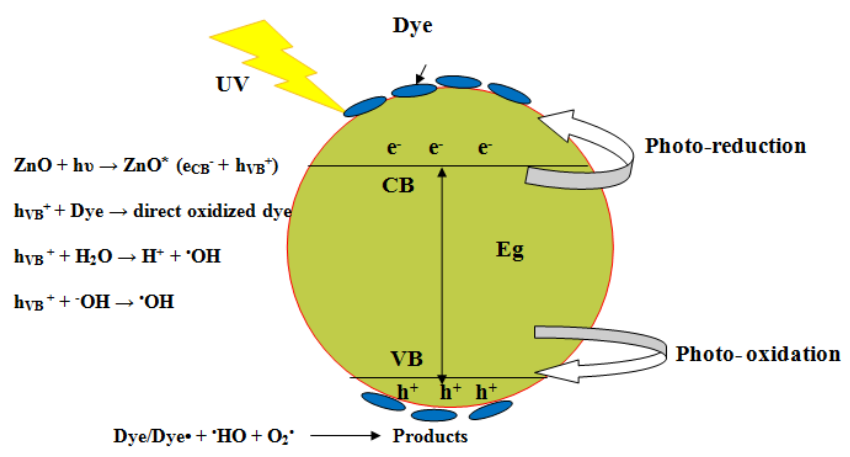

(a)

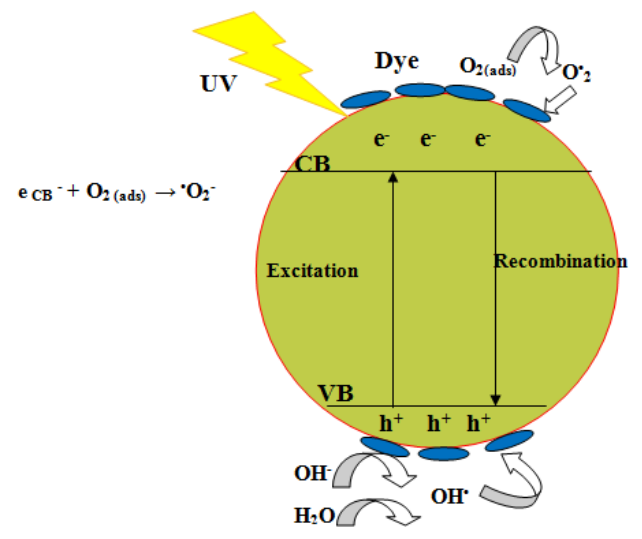

(b)

Figure 7. Mechanism of the reaction (a)direct oxidation of the dye molecules (b) oxidation of the dye molecules through the ${ }^{\circ} \mathrm{OH}$ radicals generated. 
The difference in mechanism of photocatalytic reaction between the bulk and nanoparticle material should be highlighted. In the bulk material, when the electron absorb a light it will be excited and transferred to the conduction band where high density state with different kinetics energies are there. Meanwhile, for nanoparticles materials with its smaller size, the electron and hole generated upon irradiation cannot fit into such a particle unless they assume a state of higher kinetic energy (18).

\section{Conclusions:}

The $\mathrm{ZnO}$ nanoparticles were synthesized in one step using pomegranate peels extracts. Different characterization techniques were used to characterize the prepared catalyst. The finger print of XRD for the green synthesized ZnO NPs catalyst improved the formation of hexagonal wurtzite phase structure for $\mathrm{ZnO}$ with high crystallanity and average crystalline size of $28 \mathrm{~nm}$. The FTIR for the pomegranate peels extract shows different functional groups that can react with zinc acetate which was used as zinc source during the preparation method to produce the $\mathrm{ZnO}$ nanoparticles. The diffuse reflectance spectra for $\mathrm{ZnO}$ prepared with pomegranate peels extract shows a blue shift towards short wave length compared to bare $\mathrm{ZnO}$ thus, improved the formation of nano-scale due to the size quantization phenomena. The AFM technique detects the surface morphology of $\mathrm{ZnO}$ that was not smooth with average roughness value of $6.26 \mathrm{~nm}$. The decolorization efficiency for the removal of methylene blue dye was investigated under sun light irradiation. The catalytic activity was about $88 \%$ after $60 \mathrm{~min}$ of reaction. This result was compared with the catalytic activity of bare $\mathrm{ZnO}$ synthesized without the addition of pomegranate extracts and the decolriztion efficiency was $86 \%$ after $60 \mathrm{~min}$ of sun light irradiation. The similarity in decolorization efficiency for both prepared $\mathrm{ZnO}$ catalyst synthesized with / without the pomegranate peels extract was attributed to the slight difference in their energy band gap. Further researches must be done in the future to investigate the effect of amount addition of peels extract on physical, chemical and optical properties of the prepared $\mathrm{ZnO}$.

\section{Author's declaration:}

- Conflicts of Interest: None.

- I hereby confirm that all the Figures and Tables in the manuscript are mine. Besides, the Figures and images, which are not mine, have been given the permission for re-publication attached with the manuscript.

- Ethical Clearance: The project was approved by the local ethical committee in AL-Nahrain University.

\section{References:}

1. Aminuzzaman M, Ying LP, Goh WS, Watanabe A. Green synthesis of zinc oxide nanoparticles using aqueous extract of Garcinia mangostana fruit pericarp and their photocatalytic activity. Bull Mater Sci. 2018; 41: 50 .

2. Bejarano-Perez NJ, Suarez-Herrera M F, Sonophotocatalytic degradation of congo red and methyl orange in the presence of $\mathrm{TiO}_{2}$ as a catalyst. Ultrason. Sonochem. 2007; 14: 589-595.

3. Gopinath KP, Muthukumar K, Velan M. Sonochemical degradation of Congo red: Optimization through response surface methodology. Chem Eng J. 2010; 157: 427-433.

4. Zhua H, Jianga R, Xiaob L, Changb Y, Guana Y, $\mathrm{Li} \mathrm{X}$, et al. Photocatalytic decolorization and degradation of Congo Red on innovative crosslinked chitosan/nano-CdS composite catalyst under visible light irradiation. J Hazard Mater. 2009; 169: 933940.

5. Bonancea CE, Nascimento GM, de Souza M L, Temperini M L A, Corio P. Substrate development for surface-enhanced Raman study of photocatalytic degradation processes: Congo red over silver modified titanium dioxide films. Appl Catal BEnviron. 2006; 69: 34-42.

6. Hachem C, Bocquillon F, Zahraa O, Bouchy, M. Decolourization of textile industry wastewater by the photocatalytic degradation process. Dyes Pigments. 2001; 49: 117-125.

7. Movahedi M, Mahjoub AR, and Janitabar-Darzi S. Photodegradation of Congo Red in Aqueous Solution on $\mathrm{ZnO}$ as an Alternative Catalyst to $\mathrm{TiO}_{2}$. J. Iran. Chem. Soc. 2009; 6 (3): 570-577.

8. Agarwal H, Venkat Kumar SV, Rajeshkumar S. A review on green synthesis of zinc oxide nanoparticles -An eco-friendly approach. Resource-Efficient Technologies. 2017; 3: 406-413.

9. Jamdagni P, Khatri P, Rana JS. Green synthesis of zinc oxide nanoparticles using flower extract of Nyctanthes arbor-tristis and their antifungal activity. JKSUS. 2018; 30: 168-175.

10. Adelere I A, Lateef A. A novel approach to the green synthesis of metallic nanoparticles: the use of agrowastes, enzymes, and pigments. Nanotechnol Rev. 2016; 5(6): 567-587.

11. Mishra V, Sharma R. Green Synthesis of Zinc Oxide Nanoparticles Using Fresh Peels Extract of Punica granatum and its Antimicrobial Activities. IJPRHS. 2015; 3 (3): 694-699.

12. Alwash AH. Study on the Catalytic Activity of Cerium/Cadmuim Mixed Oxide Catalysts for the Photo catalytic Degradation of Orange G Dye. NJES. 2017; 20(1):71 - 79 . 
13. Ghidan AY, Al-Antary TM, Salem NM, Awwad AM. Facile Green Synthetic Route to the Zinc Oxide (ZnONPs) Nanoparticles: Effect on Green Peach Aphid and Antibacterial Activity. J. of Agri. Sci. 2017; 9 (2).

14. Fuku X, Diallo A, Maaza M. Nanoscaled Electrocatalytic Optically Modulated $\mathrm{ZnO}$ Nanoparticles through Green Process of Punica granatum L. and Their Antibacterial Activities. Inter. J. Electroch. 2016; 2016: Article ID 4682967, 10 pages

15. Mohammadian M, Es'haghi Z, Hooshmand S. Green and chemical synthesis of zinc oxide nanoparticles and size evaluation by UV-vis spectroscopy. J Nanomed Res. 2018;7(1): 00175

16. Hassan SS M, El Azab W I M, Ali HR., and Mansour M S M. Green synthesis and characterization of $\mathrm{ZnO}$ nanoparticles for photocatalytic degradation of anthracene. Advances in Natural. Sciences. Nanosci Nanotechnol. 2015; 6: 11.

17. Kumar V, Sharma S, Sharma TP, Singh V. Band gap determination in thick films from reflectance measurements. Opt. Mater. 1999; 12: 115-119.

18. Beydoun D, Amal R, Low G, McEvoy S. Role of nanoparticles in photocatalysis. JNR. 1999; 1: 439458.
19. Varughese G, Jithin P W, Usha KT. Determination of optical band gap energy of wurtzite $\mathrm{ZnO}$ : Ce nanocrystallites. PSIJ. 2015; 5 (2) :146-154.

20. Alwash AH, Abdullah A Z, Ismail N. TiO 2 -Zeolite $\mathrm{Y}$ Catalyst Prepared Using Impregnation and IonExchange Method for Sonocatalytic Degradation of Amaranth Dye in Aqueous Solution. Inter. J. Chem. Mol. Eng. 2013;7(6):758-766.

21. Radović MD, Mitrović JZ, Kostić MM, Bojić DV, Petrović, MM, Najdanović SM, et al. Comparison of ultraviolet radiation/hydrogen peroxide, Fenton and photo-Fenton processes for the decolorization of reactive dyes. Hem. Ind. 2015; 69 (6): 657-665.

22. Augugliaro V, Litter M, Palmisano L, Soria J. The combination of heterogeneous photocatalysis with chemical and physical operations: A tool for improving the photoprocess performance. J Photoch Photobio C. 2006; 7:127-144.

23. Chen X, Wu Z, Liu D, Gao Z. Preparation of ZnO Photocatalyst for the Efficient and Rapid Photocatalytic Degradation of Azo Dyes. Nanoscale Res Lett. 2017; 12: 143.

\section{تصنيع اوكسيد الزنك النانوي كعامل مساعد ضوئي باستخدام مستخلص قشر الرمان لازالة صبغة المثلين الزرقاء}

\section{أثثيل علوش}

$$
\text { قسم الكيمياء، كلية العلوم، جامعة النهرين، بغداد، العراق }
$$

تهدف الدر اسة الى تحضير جسيمات أوكسيد الزنك باستخدام مستخلص قشر الرمان الذي بدوره يتفاعل مع ملح خلات الزنك بوجود التود

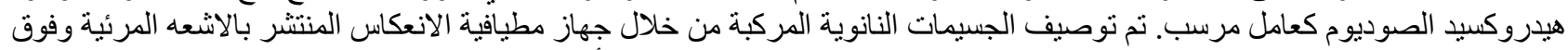

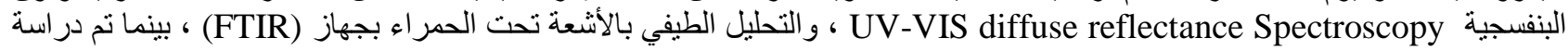

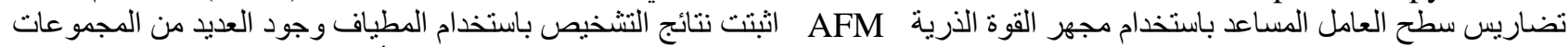

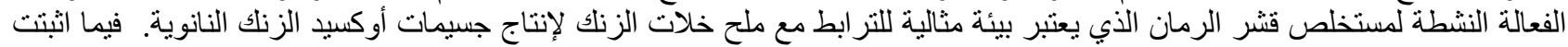

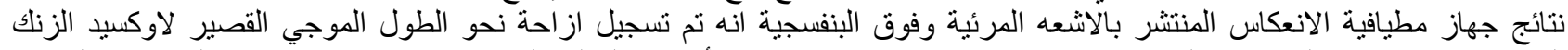

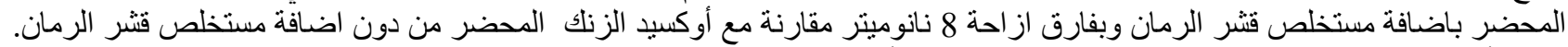

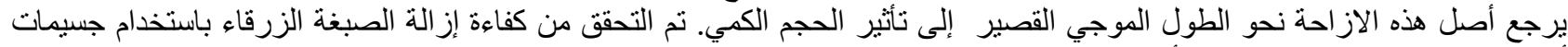

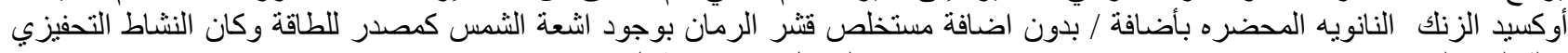
عاليًا لكلا المحفزين وبو اقع كفاءه 88\% بعد مرور 60 دقيقه من التفاعل تحت الشعة الثمس.

$$
\text { الكلمات المفتاحية: التفاعلات الضوئية، الصناعات الصديقة للبيئه، أوكسيد الزنلك، صبغة المثلين الزرقاء، قنتور الرمان. }
$$

